\title{
Successful transradial intervention via a radial recurrent artery branch from the radioulnar alpha loop using a sheathless guiding catheter
}

\author{
Shin-Eui Yoon ${ }^{1}$, Sangwook Park ${ }^{2}$, Sung Gyun $\mathrm{Ahn}^{2}$ \\ ${ }^{I}$ Division of Cardiology, Department of Internal Medicine, Daejeon Veterans Hospital, Daejeon; ${ }^{2}$ Division of Cardiology, \\ Department of Internal Medicine, Yonsei University Wonju College of Medicine, Wonju, Korea
}

The radial artery is generally the preferred access route in coronary angiography and coronary intervention. However, small size, spasm, and anatomical variations concerning the radial artery are major limitations of transradial coronary intervention (TRI). We describe a successful case involving a patient with coronary artery disease who underwent TRI via a well-developed radial recurrent artery branch from the radioulnar alpha loop using a sheathless guiding catheter.

Keywords: Percutaneous coronary intervention; Radial artery; Vascular access

\section{INTRODUCTION}

For coronary angiography and coronary intervention, the radial artery (RA) is the preferred access route over the femoral artery as hemostasis is easier, potentially leading to a reduction in bleeding and vascular access-related complications, as well as earlier mobilization [1,2]. However, the transradial approach can be challenging in patients with a small-sized RA, especially when a large-sized guiding catheter (GC) is required for percutaneous coronary intervention (PCI) of complex coronary lesions such as left main coronary stenosis, bifurcated lesions and chronic total occlusion [3]. In addition, anatomical variations in the RA comprise a major cause of failure in transradial coronary intervention (TRI) [4]. Fortunately, technological advances such as the sheathless GC system (Sheathless Eaucath, Asahi Intecc, Aichi, Japan) and the

Received: May 1 2017, Revised: July 21, 2017

Accepted: July 28, 2017

Corresponding Author: Sung Gyun Ahn, Division of Cardiology, Department of Internal Medicine, Yonsei University Wonju College of Medicine, Wonju Severance Christian Hospital, 20, Ilsan-ro, Wonju 26426, Korea

Tel: +82-33-741-0907, Fax: +82-33-741-1219

E-mail: sgahn@yonsei.ac.kr miniaturization of devices have enhanced the success rate of TRI, even in patients with a small RA and problematic anatomical variations of the RA [5,6]. We report here a case involving a patient with coronary artery disease successfully treated by TRI via a well-developed radial recurrent artery branch from the radioulnar alpha loop using a sheathless GC.

\section{CASE}

A 74-year-old man presented to our hospital with new-onset chest pain starting 4 days prior. He was on anti-hypertensive medications. No other risk factors were present. His blood pressure was 148/94 $\mathrm{mmHg}$, and his electrocardiogram revealed no significant ST-segment or T-wave changes. His left ventricular ejection fraction was $61 \%$.

Coronary angiography was performed via a transradial approach. The left RA was punctured using the Seldinger method and a 5 Fr Terumo arterial introducer sheath was inserted. Sheath angiography revealed a radial alpha loop and a radial recurrent artery branch (Fig. 1A, arrows indicate a radial recurrent artery) that follows the medial side of the brachial artery and fuses with the axillary artery (Fig. 1B, 1C). A 4 Fr JL 4.0 diagnostic catheter and a 4 Fr AL diagnostic catheter

Copyright (C) 2018 Yeungnam University College of Medicine

This is an Open Access article distributed under the terms of the Creative Commons Attribution Non-Commercial License (http://creativecommons.org/licenses/by-nc/4.0/) which permits unrestricted non-commercial use, distribution, and reproduction in any medium, provided the original work is properly cited. 
were used for left and right coronary angiography. Left coronary angiography revealed diffuse significant lesions in the proximal to mid left anterior descending artery (LAD) (Fig. 2A). Right coronary angiography showed tubular 60-70\% diameter stenosis in the mid to distal right coronary artery (RCA) (Fig. 2B). TRI via the radial recurrent artery branch was planned as it has a large enough lumen for the passage of a sheathless GC. A 6.5 Fr SPB sheathless GC was advanced smoothly via the radial recurrent artery (Fig. 1B, 1C) and placed into the ostium of the left main coronary artery. A 0.014" floppy SION blue guidewire (Asahi Intecc, Aichi, Japan) was steered into the distal LAD. Intravascular ultrasound (IVUS) was used to evaluate the vessel size and lesion length, as well as the stability of the atheroma state, and to optimize stent deployment. IVUS examination revealed severe plaque accumulation with a lesion minimum lumen area of $1.6 \mathrm{~mm}^{3}$, an external elastic membrane area of $11.9 \mathrm{~mm}^{3}$, and a plaque burden of $86.6 \%$ (Fig. 2A). Pre-dilation with an Empira NC balloon catheter (Cordis, Johnson \& Johnson, Warren, NJ, USA; $2.75 \times 10 \mathrm{~mm}$ at 20 ATM) was performed, after which two Xience Prime stents (Abbott Vascular, Abbott Park, IL, USA) with overlap $(3.5 \times 18$ $\mathrm{mm}, 2.75 \times 33 \mathrm{~mm}$ ) were deployed in the proximal to mid LAD. The final angiogram showed good appearance with normal distal flow, and the stent was fully expanded and well apposed to the vessel on IVUS examination (Fig. 2C). Subsequently, a 6.5 Fr JR 3.5 sheathless GC was engaged into the ostium of the RCA. A 0.014" floppy SION blue guidewire was passed into the distal RCA. Upon IVUS examination, diffuse fibrous plaque accumulation with calcification was observed. The lesion minimum lumen area, external elastic membrane area, and plaque burden measured $2.2 \mathrm{~mm}^{3}, 15.3 \mathrm{~mm}^{3}$ and $85.6 \%$, respectively (Fig. 2B). Pre-dilation was conducted, followed by implantation of a Xience Prime stent $(3.5 \times 18 \mathrm{~mm}$ at 18 ATM) in the mid to distal RCA. Post-stent angiography and IVUS showed a good appearance without any stent-related complications (Fig. 2D). The total procedure time was $63 \mathrm{~min}$. The patient was comfortable during the procedure, and hemostasis was successful without any vascular complications.

\section{DISCUSSION}

The RA is currently regarded as an alternative or default vascular access site for coronary procedures. However, larger introducer sheaths and GCs cannot be used in patients with a small RA, as over-sized sheaths (in relation to the size of the RA) may contribute to acute arterial occlusions [7,8]. TRI can be challenging in East Asian patients, who tend to have a somewhat small RA. Indeed, the mean RA diameter is 2.60
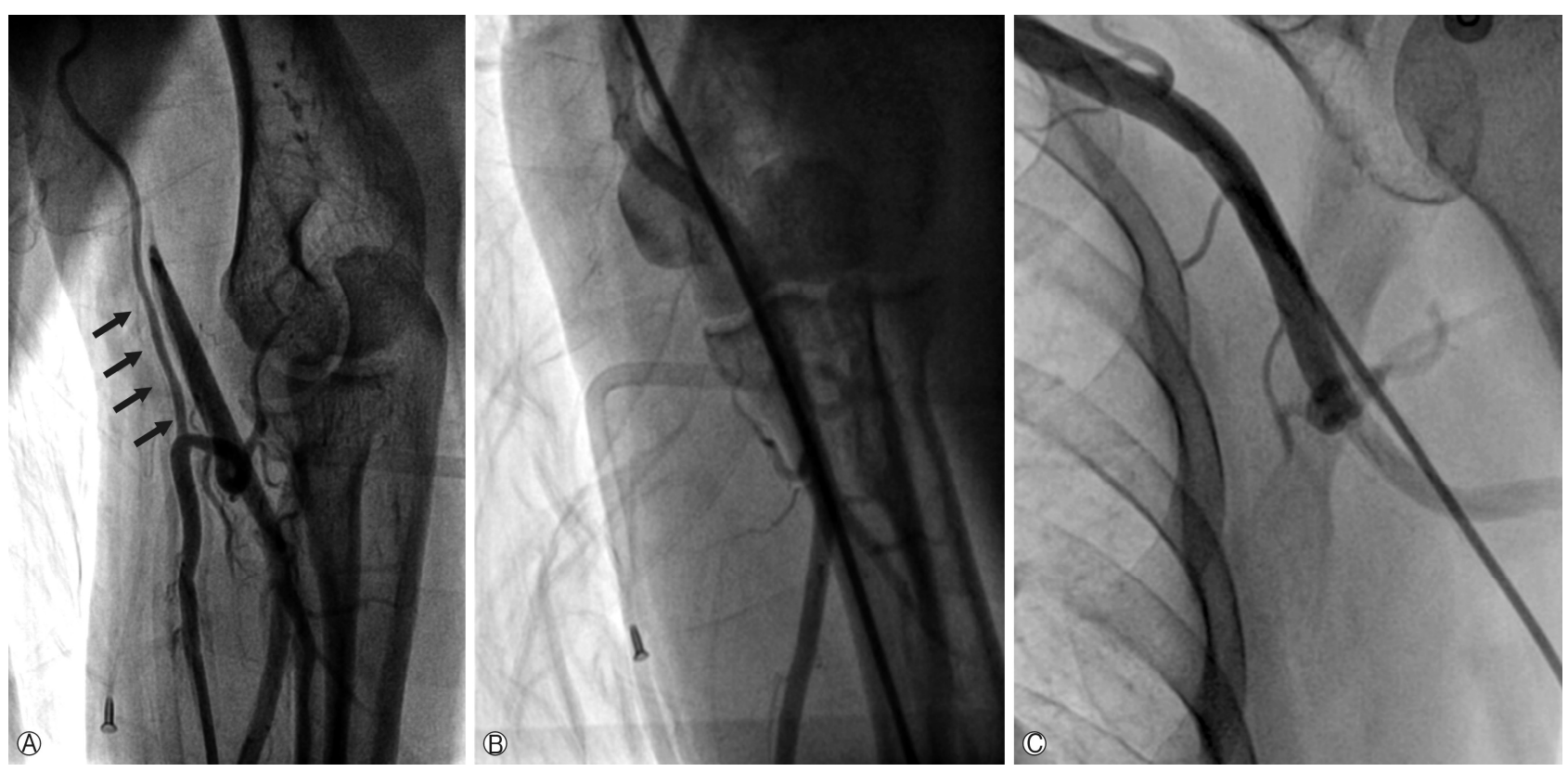

Fig. 1. A radial recurrent artery originating from the radioulnar alpha loop. Left radial angiography (A) shows the radioulnar alpha loop and a well-developed recurrent radial artery (arrows) running parallel to the brachial artery (B, C). 
$\pm 0.41 \mathrm{~mm}$ in Korean patients; thus, the lumen of the RA is frequently smaller than the outer diameter of a $6 \mathrm{Fr}$ radial sheath $[9,10]$. Anatomical variations of the RA comprise another barrier to successful TRI [11,12]. The failure rate of TRI is considerably high (17-37\%) in patients with a radioulnar alpha loop [7,13,14].

The presence of a radioulnar loop is the most common cause of TRI failure. Although the loops can be overcome using hydrophilic wires [15], it can be difficult to straighten the loop when the patient has a tight retrograde bend in the
RA of over $180^{\circ}$ before joining the ulnar artery and a stiff right angle just before the loop, as in the present case (Fig. 1A). Although a transfemoral approach could be favorable for time saving or safety in this case, we selected TRI in consideration of the patient's convenience and somewhat adequate size of the radial recurrent artery. We postulated that a radial recurrent artery with the same driving direction of the brachial artery was a viable option for TRI; thus, a $6.5 \mathrm{Fr}$ sheathless GC was selected to pass through the radial recurrent artery (Fig. 1B, 1C). The sheathless GC system (Fig. 3) is composed of a
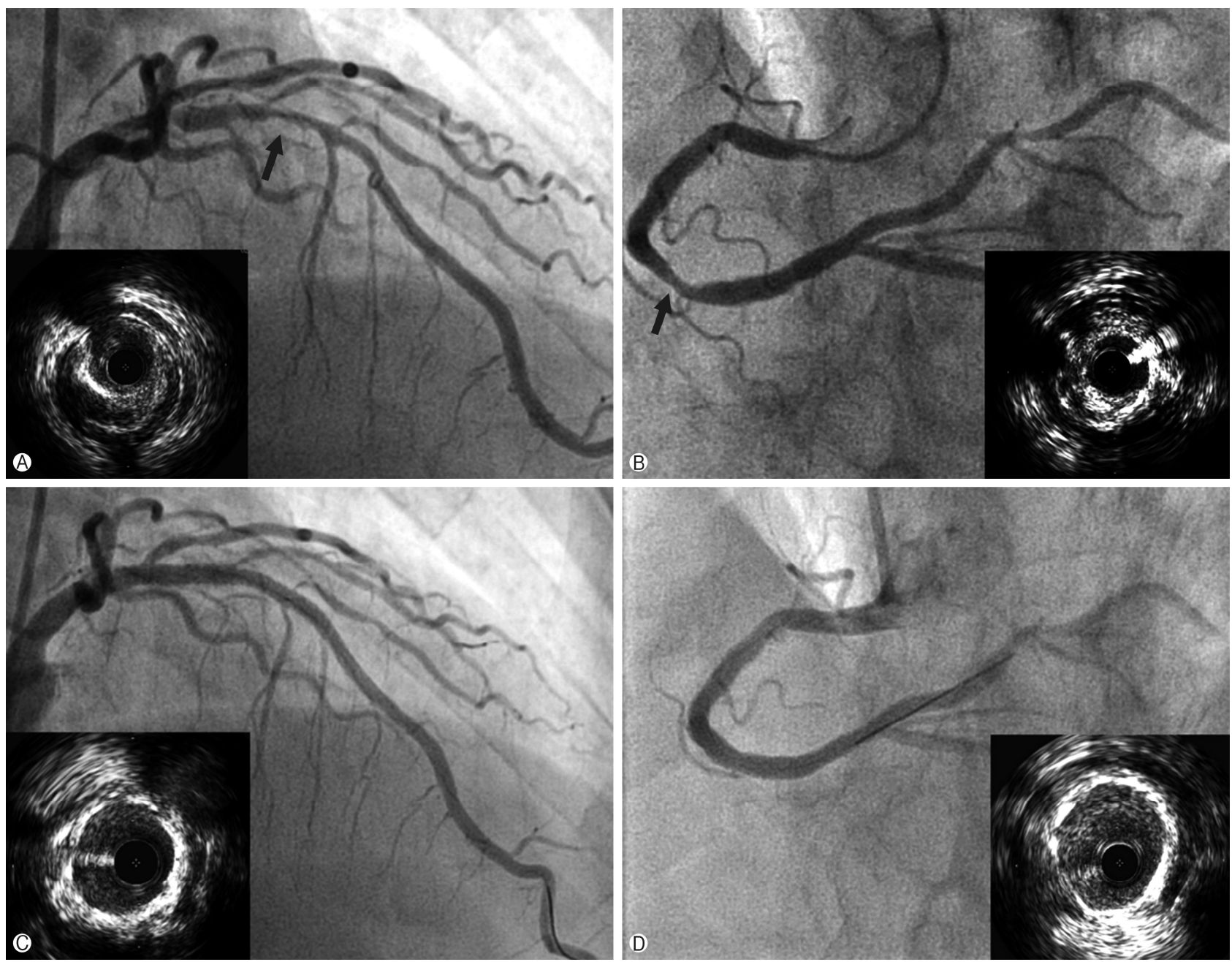

Fig. 2. Coronary angiography and intravascular ultrasound. Left coronary angiography (A) reveals diffuse significant stenosis in the proximal to mid LAD (arrow). IVUS examination (left low in A) showed severe plaque accumulation with a lesion minimum lumen area of $1.6 \mathrm{~mm}^{3}$, an external elastic membrane area of $11.9 \mathrm{~mm}^{3}$, and a plaque burden of $86.6 \%$. Right coronary angiography (B) shows tubular $60-70 \%$ stenosis in the mid to distal right coronary artery (arrow). IVUS examination (right low in B) showed diffuse fibrous plaque accumulation with calcification. The lesion minimum lumen area, external elastic membrane area, and plaque burden measured 2.2 $\mathrm{mm}^{3}, 15.3 \mathrm{~mm}^{3}$ and $85.6 \%$, respectively. Post-stent angiography of LAD $(\mathrm{C})$ and IVUS showed good appearance, and well apposed and fully expanded stent (left low in C). Post-stent angiography of right coronary artery and IVUS showed good appearance, and well apposed and fully expanded stent (D). LAD, left anterior descending artery; IVUS, intravascular ultrasound. 


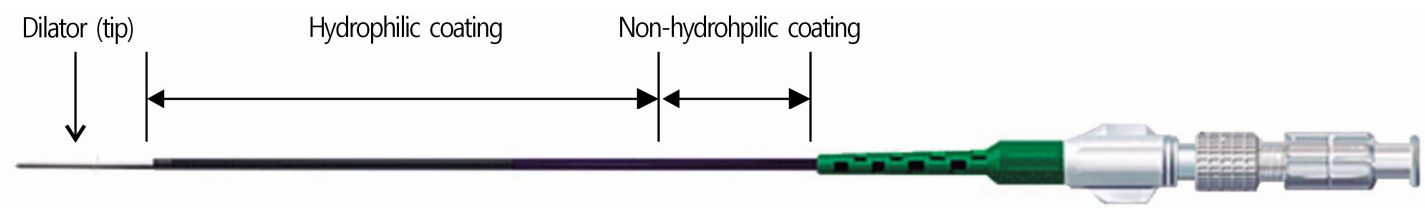

Sheathless Guiding Catheter $\quad$ Proximal Dilator \& Catheter Dock

$\begin{array}{cccccc}\text { 5F Guide } & \text { 6F Guide } & \text { 6.5F Sheathless Eaucath } & \text { 5F Radial Sheath } & \text { 7.5F Sheathless Eaucath } & \text { 6F Radial Sheath } \\ \text { OD } 1.67 \mathrm{~mm} & \text { OD } 1.98 \mathrm{~mm} & \text { OD } 2.16 \mathrm{~mm} & \text { OD } 2.29 \mathrm{~mm} & \text { OD } 2.49 \mathrm{~mm} & \text { OD } 2.52 \mathrm{~mm} \\ \text { ID } 1.47 \mathrm{~mm} & \text { ID } 1.80 \mathrm{~mm} & \text { ID } 1.78 \mathrm{~mm} & \text { ID } 1.67 \mathrm{~mm} & \text { ID } 2.06 \mathrm{~mm} & \text { ID } 1.98 \mathrm{~mm}\end{array}$

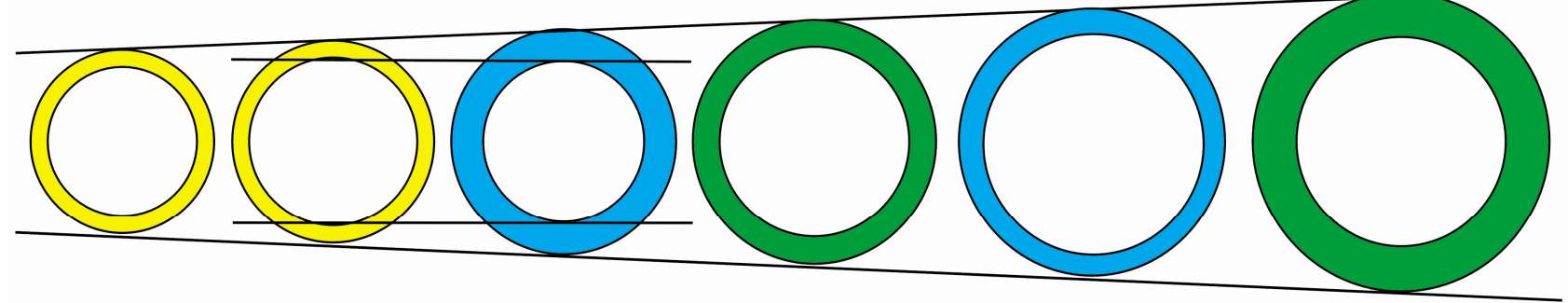

Fig. 3. The sheathless guiding catheter system and its lumen size. The sheathless GC system is composed of a hydrophilic guiding catheter and a long central dilator. The 6.5 Fr sheathless GC has an outer diameter $(2.16 \mathrm{~mm})$ smaller than that of a 5 Fr introducer sheath $(2.29 \mathrm{~mm})$, with an inner diameter $(1.78 \mathrm{~mm})$ similar to that of a 6 Fr GC $(1.78-1.8 \mathrm{~mm})$. GC, guiding catheter; OD, outer diameter; ID, inner diameter.

hydrophilic guiding catheter and a long central dilator, and has several beneficial features: (1) the hydrophilic coating and relatively small outer diameter reduce spasms and forearm discomfort; and (2) an adequate inner diameter enables TRI for most complex coronary lesions. The 6.5 Fr sheathless GC has an outer diameter $(2.16 \mathrm{~mm})$ smaller than that of a $5 \mathrm{Fr}$ introducer sheath $(2.29 \mathrm{~mm})$, with an inner diameter (1.78 $\mathrm{mm})$ similar to that of a 6 Fr GC $(1.78-1.8 \mathrm{~mm})$. While remaining the $5 \mathrm{Fr}$ introducer sheath, a $5 \mathrm{Fr}$ guiding catheter can also be selected for this patient. However, it has some procedural limitations due to the smaller inner lumen diameter $(1.47 \mathrm{~mm})$ compared to that of the 6.5 Fr sheathless GC. Moreover, the hydrophilic coating of the sheathless GC system might facilitate passage through the radial recurrent artery. Accordingly, the use of a sheathless GC maintains the benefits of a traditional 6 Fr GC, including increased support and compatibility with a wide range of adjunctive devices and complex PCIs. Sheathless GCs are particularly useful for patients with a small RA, regardless of lesion complexity or severity [5].

The present case is unique in that we successfully performed TRI using a sheathless GC via a radial recurrent artery rather than overcoming the radioulnar alpha loop. Knowledge regarding anatomical variations of the radial and brachial arteries and proper device selection are both prerequisites for a successful TRI. In conclusion, the sheathless GC system is likely a viable option for TRI in patients with a radial alpha loop and well-developed radial recurrent artery, as well as patients with a small and spastic RA.

\section{CONFLICT OF INTEREST}

No potential conflict of interest relevant to this article was reported.

\section{ORCID}

Shin-Eui Yoon, https://orcid.org/0000-0003-3507-7254

Sangwook Park, https://orcid.org/0000-0003-4871-1461

Sung Gyun Ahn, https://orcid.org/0000-0002-1528-2739

\section{REFERENCES}

1. Jolly SS, Amlani S, Hamon M, Yusuf S, Mehta SR. Radial versus femoral access for coronary angiography or intervention and the impact on major bleeding and ischemic events: a systematic review and meta-analysis of randomized trials. Am Heart J 2009;157:132-40.

2. Pristipino C, Trani C, Nazzaro MS, Berni A, Patti G, Patrizi $\mathrm{R}$, et al. Major improvement of percutaneous cardiovascular procedure outcomes with radial artery catheterization: results 
from the PREVAIL study. Heart 2009;95:476-82.

3. Saito S, Miyake S, Hosokawa G, Tanaka S, Kawamitsu K, Kaneda H, et al. Transradial coronary intervention in Japanese patients. Catheter Cardiovasc Interv 1999;46:37-41.

4. Franchi E, Marino P, Biondi-Zoccai GG, De Luca G, Vassanelli C, Agostoni P. Transradial versus transfemoral approach for percutaneous coronary procedures. Curr Cardiol Rep 2009;11:391-7.

5. Youn YJ, Yoon J, Han SW, Lee JW, Sung JK, Ahn SG, et al. Feasibility of transradial coronary intervention using a sheathless guiding catheter in patients with small radial artery. Korean Circ J 2011;41:143-8.

6. Mamas M, D'Souza S, Hendry C, Ali R, Iles-Smith H, Palmer $\mathrm{K}$, et al. Use of the sheathless guide catheter during routine transradial percutaneous coronary intervention: a feasibility study. Catheter Cardiovasc Interv 2010;75:596-602.

7. Stella PR, Kiemeneij F, Laarman GJ, Odekerken D, Slagboom $\mathrm{T}$, van der Wieken $\mathrm{R}$. Incidence and outcome of radial artery occlusion following transradial artery coronary angioplasty. Cathet Cardiovasc Diagn 1997;40:156-8.

8. Dahm JB, Vogelgesang D, Hummel A, Staudt A, Völzke H, Felix SB. A randomized trial of 5 vs. 6 French transradial percutaneous coronary interventions. Catheter Cardiovasc Interv 2002;57:172-6.

9. Yoo BS, Yoon J, Ko JY, Kim JY, Lee SH, Hwang SO, et al. Anatomical consideration of the radial artery for transradial coronary procedures: arterial diameter, branching anomaly and vessel tortuosity. Int J Cardiol 2005;101:421-7.

10. Saito S, Ikei H, Hosokawa G, Tanaka S. Influence of the ratio between radial artery inner diameter and sheath outer diameter on radial artery flow after transradial coronary intervention. Catheter Cardiovasc Interv 1999;46:173-8.

11. Yokoyama N, Takeshita S, Ochiai M, Koyama Y, Hoshino $\mathrm{S}$, Isshiki $\mathrm{T}$, et al. Anatomic variations of the radial artery in patients undergoing transradial coronary intervention. Catheter Cardiovasc Interv 2000;49:357-62.

12. Numasawa Y, Kawamura A, Kohsaka S, Takahashi M, Endo A, Arai T, et al. Anatomical variations affect radial artery spasm and procedural achievement of transradial cardiac catheterization. Heart Vessels 2014;29:49-57.

13. Lo TS, Nolan J, Fountzopoulos E, Behan M, Butler R, Hetherington SL, et al. Radial artery anomaly and its influence on transradial coronary procedural outcome. Heart 2009;95: 410-5.

14. Valsecchi O, Vassileva A, Musumeci G, Rossini R, Tespili M, Guagliumi G, et al. Failure of transradial approach during coronary interventions: anatomic considerations. Catheter Cardiovasc Interv 2006;67:870-8.

15. Louvard Y, Lefèvre T. Loops and transradial approach in coronary diagnosis and intervention. Catheter Cardiovasc Interv 2000;51:250-2. 